\title{
Investigation of the Physical Learning Environment of Distance Learning Under COVID-19 and Its Influence on Students' Health and Learning Satisfaction
}

\author{
(iD) https://orcid.org/0000-0001-8833-2701 \\ Wu-Yuin Hwang, National Central University, Zhongli, Taiwan \\ Timothy K. Shih, National Central University, Zhongli, Taiwan
}

Lixin Zhao, National Central University, Zhongli, Taiwan \& Beijing Normal University, Zhuhai, China

\begin{abstract}
Most undergraduates in Mainland China receive distance education from home because of the COVID-19 outbreak. The unique physical environment of distance learning may have effects not only on student learning but also on student physical and mental health. This study reviewed related studies of the physical learning environment and its influence on learners' physical and mental health. Using factor analysis, the authors developed a questionnaire to measure students' perceptions towards their physical learning environment and their physical and mental health and verified the reliability. Regression analysis was used to explore the influence of physical environment perception on physical health and mental health perception, as well as the predictive ability of these three factors on learning satisfaction. The results of this study provide researchers and educators with insight into learners' perceptions of the physical learning environment and their physical and mental health under COVID-19 and offer suggestions for improving distance-learning satisfaction.
\end{abstract}

\section{KEYWORDS}

COVID-19, Distance Learning, Higher Education, Learning Satisfaction, Mental Health, Physical Environment, Physical Health, Physical Learning Environment

\section{INTRODUCTION}

Distance education has been developing for many years, and today online education provided over the Internet, such as through video classrooms, seminars, and YouTube instructional videos, is becoming a trend. However, online education has always been a supplement to formal higher education, as most students are still receiving higher education face-to-face on campus, and only part of the courses are taught online. It is rare to see formal undergraduate degree programs that adopt the model of online education off campus for all courses, which is referred to as "exclusively" distance education in this

DOI: 10.4018/IJDET.20210401.oa4

This article published as an Open Access article distributed under the terms of the Creative Commons Attribution License (http://creativecommons.org/licenses/by/4.0/) which permits unrestricted use, distribution, and production in any medium, provided the author of the original work and original publication source are properly credited. 
paper (Allen \& Seaman, 2017). Due to the COVID-19 outbreak in January 2020, almost all college students in China were forced to receive online education at home in the Spring semester of 2020, allowing the researchers to explore the performance and perceptions of full-time undergraduate students receiving "exclusively" distance education.

When college students receive online education at home, they are in a physical learning environment (PLE) totally different from campuses or classrooms where they receive formal education. Studies have shown that the physical environment can affect the thoughts, emotions, behaviours, performance, and satisfaction of workers (Alphonse, Orellana, \& Kanzki-Veloso, 2019), so can it also affect the learning behaviours, emotions, satisfaction, and academic performance of learners (Higgins, Hall, Wall, Woolner, \& McCaughey, 2005; Hunley \& Schaller, 2009; Tanner, 2008). An increasing number of studies have noted the importance of physical space in education settings (Cleveland \& Fisher, 2014). In addition, some studies have shown that the physical health, mental health, and emotions of learners can also be affected by the physical environment, thus influencing their satisfaction in learning and their academic performance (Shadiev, Hwang, \& Liu, 2018). Choi, Van Merriënboer, and Paas (2014) pointed out that a high-quality physical environment has a positive influence on emotions and the willingness of learning hard, and that emotional state, mood, and motivation, are the mediating variables between the physical environment and the academic performance. A terrible physical environment may have a negative influence on the emotional state of learners, such as discomfort or a decrease in the willingness to study.

Existing studies on the influence of the physical environment on learning primarily focus on campus environment, with a focus on formal education, but few studies paid attention to the physical environment of online education. The outbreak of COVID-19 has added new variables and attracted more attention to the physical environment of online education since many students are asked to participate in online education at home. Additionally, there are diversified characteristics of the physical environments at home for each student. Therefore, this study aims to explore how students identify characteristics of the physical environment that can affect their learning and health under the influence of COVID-19, which factors of physical health and mental health may act as the mediating variables of the physical environment and the learning satisfaction, and how these factors affect the satisfaction of the students participating in online education.

\section{THE PLE IN DISTANCE EDUCATION}

One of the focus points of existing studies on learning environment is the study of social and social psychological environment. For example, Cleveland \& Fisher (2014) reviewed 9 questionnaires on the social psychological environment of classroom learning, which measured such social psychological environmental factors as cohesiveness, diversity, independence, and teacher support. The few studies on the environment of online education also focused on social psychological environment and interaction. Sahin (2007) developed a distance education learning environments survey (DELES) to analyse the characteristics of online learning environments. Trinidad, Aldridge, and Fraser (2005) integrated the four existing scales and developed the online learning environment survey (OLES), a tool to measure the learning environment perception in e-learning, involving eight factors. However, neither of their studies took into account the physical environment.

Most studies on the PLE focus on formal on-campus environments, such as classrooms and libraries, where flexibility, comfort, perception, stimulation, and technical functionality are emphasized in the design (Chism, 2006). Miller (2009) emphasized the importance of having physical learning space and a comfortable environment, which depends on temperature, light, furniture, and facilities. There are many studies on the evaluation of the PLE in formal education, focusing mainly on the design of the physical learning space from an ergonomic perspective (Alphonse et al., 2019). Evaluation of the PLE of classrooms from the ergonomic perspective is generally based on systematic observation, and one of the widely used instruments of observation is a specially developed ergonomic inventory 
known as the computerized classroom ergonomic inventory (CCEI) (Zandvliet \& Fraser, 2004, 2005). In this approach, the physical environmental variables found in the classroom are discretely measured and marked, and a hierarchical rating scale (scored out of five) is used to evaluate the matching of these physical environmental variables and existing ergonomic guidelines. CCEI integrates the PLE factors into the following five aspects: Workspace Environment; Computer Environment; Visual Environment; Spatial Environment and, Overall Air Quality. In addition, based on the methods of physical space evaluation in ergonomics, such factors as the number of computers, layout of the room, luminance, content of carbon dioxide, average temperature, and relative humidity, are measured. Zandvliet \& Fraser $(2004,2005)$ provided a detailed list of the ergonomic work covering all of these factors.

Cleveland and Fisher (2014) critically reviewed the methodologies and methods used to evaluate the PLE and came up with the post-occupancy evaluation (POE) for the evaluation of non-domestic buildings, aiming to provide the most appropriate way to evaluate the contemporary PLE. Preiser (1995) came up with three general POE methodologies: indicative, investigative and diagnostic; the data collection methods used included: interviews, checklists, questionnaires, systematic observation, participant observation, critical incidents, and archival record analysis. Leaman et al. (2010) added some updated methods of data collection: expert walk-throughs; measuring technical performance of building fabric, services and systems; assessing environmental performance; occupant survey questionnaires; structured discussion interviews with participants and; and visually recording matters related to the aforementioned points (photos, video, thermo-graphic images).

The evaluation of the PLE on campus, in the existing studies, aim to improve the architectural design of the learning environment on campus, help justify the investment, and create a good universal learning space on campus (Alphonse et al., 2019). However, the physical environment affects the process of learning in rather complicated ways (Evans \& Stecker 2004; Higgins et al., 2005). Existing evaluation standards of the PLE are also rather complicated (Cleveland \& Fisher, 2014).

In this study, all learners receive online education at home, following the same teaching schedule as in school. In terms of teaching and interaction tools, the school has provided teachers and students with three types of tools:

1. A synchronous online conference system for online teaching, such as ZOOM (https://zoom. us/), ZHUMU (https://www.zhumu.com/), and Rain Classroom (https://www.yuketang.cn/). All of these systems include the functions of online video windows and chat rooms, and support PowerPoint presentations, graphic/voice/video communication, as well as live speech and recording, and playbacks of live content for all participants.

2. Teachers can publish assignments and course materials with the website of the school and the online teaching aid system and organize students to participate in asynchronous discussions outside of class time through the discussion board. Students can also obtain information and course materials from the website of the school and the online teaching aid system.

3. Daily communication between learners and their classmates, teachers and school staff can be realized through instant messaging software such as WeChat, QQ, and other popular social network platforms.

In terms of learning space, educators cannot provide uniform teaching space for all students, because most students study at home. The PLE of learners is limited by the conditions of their families, so students can only choose the learning space according to the conditions available. These learning spaces are very complex, and it is impossible for the researchers to carry out field visits and measurement. One of the objectives of this study is to explore the characteristics of the discretely distributed learners' informal physical learning space and technical conditions, and their influence on the learners' health and learning satisfaction. Therefore, based on ergonomic methodologies and interviews with students, this study developed a questionnaire for students' self-reporting of 
their subjective perception of their PLE, so as to identify online learners' perception of the physical environment of their informal learning space.

\section{PHYSICAL AND MENTAL HEALTH IN LEARNING}

As studies have shown, physical exercise has an important effect on maintaining health and positive emotions and promoting learning. Therefore, learners should participate in physical exercise to stay healthy and maintain positive emotions (Harvey et al., 2018; Shadiev et al., 2018). A lifestyle lacking physical exercise may lead to an increase in the probability of acquiring non-communicable diseases, reduce immunity, and lead to anxiety and health problems (Uher, Cimboláková, \& Pivovarník, 2016). In terms of learning, numerous studies have shown that physical exercise can help improve health and cognitive behavioural benefits, thus contributing to the improvement of academic performance (Christopher, Dzakiria, \& Mohamed, 2012; Harvey et al., 2018; Liu, Sulpizio, Kornpetpanee, \& Job, 2017; Salinas, Messias, Morales-Campos, \& Parra-Medina, 2014). During the pandemic of COVID-19, students have been learning at home to lower the risk of becoming infected, and they have reduced outdoor activities. Such a physical environment has reduced the chances of learners to participate in sports and get physical exercise, which may have negative effects on their health and increase their risks of acquiring non-communicative and/or chronic diseases (Penedo \& Dahn, 2005). Besides such factors as the temperature and the air quality of the physical environment having negative effects on student learning and satisfaction, the metabolism of the brain may also become a negative factor by influencing physiological factors (such as arterial blood oxygen saturation and blood glucose levels), thus leading to lower cognitive performance (Choi, et al., 2014). Always studying with a computer can cause harm to the eye, because the learner needs to gaze at the monitor for long time periods of time (Logaraj, Madhupriya, \& Hegde, 2014), and sitting long periods without performing any physical exercise may cause bone and muscle damage, as well as create body fat (Jones, et al., 2008; Júnior, et al., 2013).

Some studies have proven that a poor physical environment and a lack of sports can affect mental health, causing anxiety and boredom, while active and regular physical exercise can create positive mood states (e.g. enjoyment) (Choi, et al., 2014; Pekrun, 2006; Penedo \& Dahn, 2005), Also, emotions have great influence on a learner's status and behaviours. Some researchers state that negative emotions have a negative influence on health, thus they will they impede learning (Pishghadam, Zabetipour, \& Aminzadeh, 2016; Tugade, Fredrickson, \& Barrett, 2004), while positive emotions can help improve the motivation, level of effort, and level of self-regulation of learners, thus improving academic performance (MacIntyre \& Vincze, 2017; Pishghadam et al., 2016).

As a result of the somewhat negative experience caused by physical isolation from classmates and teachers during the process of distance education, the psychological factors relating to isolation and alienation have gained attention in online education (Garrison, Anderson, \& Archer, 2001; Morgan \& Tam, 1999). Cognitive psychologists believe that it is human nature to study and work through collaboration with others, and that it is impossible for learners to study in a state of isolation (Toulmin, 1978). Therefore, a learning community needs to be established in distance education to assist students in maintaining interactions and collaborations with their classmates and teachers (Laurillard, 2000).

On the whole, learners receiving distance education in the context of the COVID-19 pandemic are faced with three risks to their health: physical health (obesity, decreased vision, and lack of exercise of muscles and bones, etc.), brain fatigue (overall fatigue and memory deterioration, etc.), and COVID-19 infection (a viral infectious disease). This study combines the above factors with the results of the interviews conducted with students, and develops a questionnaire for learners' subjective perception of their own physical and mental health to identify the factors involved in the learner's perceptions about their own health status during their period of distance learning. 


\section{LEARNING SATISFACTION}

In traditional education on campus, physical and mental health both have an influence on learning, while physical environment not only influences physical and mental health, but also impacts a learners' satisfaction and academic performance, however, there are different opinions about these. For example, two studies by Zandvliet and Fraser $(2004,2005)$ have shown that there is no significant correlation, or a weak correlation, between the satisfaction of the students and the physical environmental variables of the classroom (workspace, visual environment). In contrast, a study by Liu, Zandvliet, and Hou (2012) revealed that among physical environmental factors, only spatial environment is related to satisfaction.

In order to maintain a healthy state, regular physical exercise is considered to be very important (Gijselaers, Kirschner, Verboon, \& de Groot, 2016; Malina, 2001). In addition, studies have shown that physical exercise has a positive impact on academic performance (Shadiev et al., 2018). Particularly speaking, in traditional education, physical exercise and sedentary behaviours are related to academic performance in children (Fedewa \& Ahn, 2011; Tremblay et al., 2011). However, through a literature review, no consistent conclusions have been reached regarding the relationship between adult students' physical exercise and their academic performance (Gijselaers et al., 2016). There are few studies on physical exercise and academic performance in distance education. According to the results of the study on the relationship between physical exercise, sedentary behaviour, and academic performance of students, physical exercise is not correlated with academic performance, while sedentary behaviour can predict progress in learning (Gijselaers et al., 2016). However, such progress is made at the cost of reducing physical exercise and harming health.

Considering that the satisfaction of students is viewed as being significantly correlated with academic performance (Zandvliet \& Fraser, 2004, 2005), this study focuses on the influence of physical environment, physical health, and mental health, on the learning satisfaction of the students in distance education.

\section{RESEARCH OBJECTIVES AND QUESTIONS}

Due to the COVID-19 pandemic, many full-time undergraduates in China must receive "exclusively" distance education. With the students from a Chinese university as the research subjects, this study explores the following three questions:

1. A questionnaire was developed to identify students' physical environment perception (PEP), physical health perception (PHP), and mental health perception (MHP). The reliability of the questionnaire was analysed and verified.

2. To analyse the influence of PEP on PHP and MHP.

3. To analyse the influence of PEP, PHP, and MHP on learning satisfaction.

Development of the initial items of the questionnaire is in the section of research instruments, and then explore factor analysis was used to identify underlying factors. Next, confirm factor analysis was used to verify the reliability of the questionnaire. At last, regression analysis was used to analyse the influence of PLE on health and the influence of PEP, PHP, and MHP on learning satisfaction.

\section{RESEARCH INSTRUMENTS}

\section{Questionnaire}

In order to develop the questionnaire, a gradual process was used to develop initial items. The questionnaire used in this study include four scales: PEP; PHP; MHP; learning satisfaction. This study 
is faced with two special situations. The first is that the existing relevant scales are all designed for distance learning of specific subjects and this present study involves all subjects that undergraduate study in a semester. Second, this study takes into consideration the influence of the COVID-19 pandemic on learners' perceptions of physical environment and health. Therefore, the scales of PEP, PHP, and MHP used in this study, all have been gradually improved based on a review of the literature, in-depth interviews with learners, appraisal of experts, and a pilot study. The questions on the scale of learning satisfaction have been chosen on the basis of the literature review and other scales wherein reliability was verified.

The researchers conducted a simple survey of over 120 students to gather some basic characteristics about the students, including gender, grade, academic ranking, and preference between online learning and on-campus learning. The researchers then selected a sample of 20 students that represented these characteristics and conducted an interview of 20-30 minutes with each of the students. The following questions were asked in the interviews:

- Why do you/don't you want to choose an online education?

- What influence of the physical environment and technology conditions have you perceived in the process of learning?

- What discomforts have you experienced in the process of online learning?

- What feelings and concerns do you have in terms of health?

- How do you evaluate the emotions and psychological status in online learning?

- What are you satisfied and unsatisfied about in the online learning of this semester?

Existing evaluations of the PLE are about the formal teaching environment on campus in which data of the physical environment are collected through such qualitative methods as on-spot investigations, measurements, and interviews with teachers and students (Zandvliet \& Straker, 2001). Considering that each student receiving a distance education is in his/her own private living environment, which is significantly different from the campus environment and is difficult for the researchers to observe and record the physical environment of the learners as can be done in the CCEI method, the researchers develop a questionnaire of self-reported subjective opinions of the learners to measure their perception of the PLE. The questionnaire development refers to the measurement indicators of the PLE in relevant studies of CCEI, including workspace environment, information technology environment, visual environment, spatial environment, overall air quality, noise, light, brightness, temperature, and humidity (Zandvliet \& Fraser, 2004, 2005). The initial items on PEP were determined on the basis of these indicators and the results of the student interviews.

The development of the scale of PHP was also based on the in-depth interviews and the literature review. The items of the initial questionnaire contain the following aspects: bones and muscles, obesity, eyes and skin, brain energy, virus and disease prevention. Meanwhile, the scale of MHP considers two mental health factors, respectively learning emotion and isolation. In terms of learning emotion, AEQ (Achievement Emotions Questionnaire), the simplified learning emotion scale, used in a study by Lichtenfeld, Pekrun, Stupnisky, Reiss, and Murayama (2012), was referred to, including the three dimensions of enjoyment, boredom, and anxiety. The scale of isolation in the questionnaire referred to psychological isolation (Russell, Peplau, \& Ferguson, 1978) and academic and social isolation (Erichsen \& Bolliger, 2011).

Based on the literature review and student interviews, the researchers designed the initial questionnaire to evaluate learners' perception of physical environment, physical health, and mental health. The initial questions of the scale of learning satisfaction were taken from two studies conducted by Eom, Wen, and Ashill (2006) and Arbaugh (2000). There are 42 items in the scale of PEP, 15 items in the scale of PHP, 18 items in the scale of MHP, and 6 items in the scale of learning satisfaction.

The initial questionnaire items were reviewed by five experts, all of who had more than 15 years of teaching experience and at least half a year of distance teaching experience, as well as two experts 
with more than five years of distance learning research experience and questionnaire development experience. According to the consensus of the five experts, some items with repeated, inappropriate, and irrelevant meanings in the questionnaire were deleted. After a review by the experts, 19 items in the scale of PEP were deleted, retaining 23 items; 2 items in the scale of PHP were deleted, retaining 13 items; 4 items in the scale of MHP, retaining 14 items; and all items in the scale of satisfaction were retained. A pilot study was then conducted, and 50 samples were collected, through simple sampling, for factor analysis; part of the learners participating in the survey were consulted for suggestions. After that, 9 items in the scale of PEP were deleted, 2 items were deleted from the scale of PHP, 2 items were deleted from the scale of MHP, and one item was deleted from the scale of learning satisfaction. For example, the initial questionnaire included some items such as "I have an independent learning space"(PLE), "Feeling physically unhealthy during online classes"(PHP), "Sometimes I feel irritable"(MHP), but in the analysis of the pilot study, multiple loads occurred in these item, so them were removed. In the final scales used in the formal study, there are 14 items in the scale of PEP, 11 items in the scale of PHP, 12 items in the scale of MHP, and 5 items in the scale of learning satisfaction. The items on the final questionnaire are shown in Tables 2, 3, 4, and 13.

All the four scales are Likert scales, and each survey item was measured on a five-point scale from (1) "strongly disagree" to (5) "strongly agree."

\section{METHODOLOGY}

\section{Data Collection and Analysis}

The researchers selected the students at a university in South China's Guangdong Province as the research subjects. A small part of these students has studied massive open online courses (MOOCs) out of personal interest, or studied the online courses provided by off-campus organizations in order to obtain certifications (such as the International English Language Testing System and Chinese National Computer Rank Examination). Except for this, most students had never taken any online courses. This study was performed with all students in the school as the research subjects, and no subjects or courses were chosen. In terms of the sampling method, the method of convenience sampling was adopted. Through use of the IM tool (WeChat), the questionnaire was distributed to students of different majors and grades. A total of 433 questionnaires were collected, and samples with extreme values were discarded (those choosing 5 or 1 for all questions due to half-low-level motivation to participate), thus obtaining 406 valid questionnaires.

The 406 questionnaires were randomly divided into two subsamples using the SPSS filter algorithm: sample $1(n=201$, male $=50$, female $=151)$ and sample $2(n=205$, male $=41$, female $=164$ ). For sample 1 , an exploratory factor analysis (principal component analysis with varimax rotation) was conducted to identify underlying structural factors. Next, a confirmatory factor analysis was conducted for sample 2 to verify the model fit, reliability, and validity of the measurement model. Finally, a multiple regression analysis was performed to analyse the effects of PEP on PHP and MHP, and how much these three variables predict learning satisfaction.

\section{EXPLORATORY FACTOR ANALYSIS (EFA)}

For the scale of PEP, the scale of PHP, and the scale of MHP, an EFA was conducted with sample 1 $(\mathrm{n}=201)$ to identify underlying factors. The appropriateness of factor analysis was determined by using criteria such as the Kaiser-Meyer Olkin (KMO) measure of sampling adequacy and Bartlett's test of sphericity (Sharma, 1996). The results are shown in Table 1. All the KMO of the three scales were greater than 0.7 and $p=0.000$, which indicated that the data collected by the three scales were all suitable for factor analysis (Kaiser, 1974). A principal components analysis and a rotation method 
Table 1. KMO and Bartlett's test of sphericity

\begin{tabular}{|l|l|l|l|l|}
\hline \multicolumn{1}{|c|}{ Scales } & \multicolumn{1}{c|}{ KMO } & \multicolumn{1}{c|}{ CMIN } & \multicolumn{1}{c|}{ df } & \multicolumn{1}{c|}{ p } \\
\hline Physical Environment & .789 & 1080.436 & 105 & .000 \\
\hline Physical Health & .803 & 887.508 & 55 & .000 \\
\hline Mental Health & .780 & 1354.766 & 66 & .000 \\
\hline
\end{tabular}

of varimax with Kaiser normalization was adopted in the EFA of the three scales, and the criterion of factor extraction was eigenvalue $>1$.

\section{EFA of PEP}

The EFA results of the scale of PEP are as shown in Table 2. A total of four factors were extracted, together accounting for $62.3 \%$ of the total variance, and factor loading of all items was higher than 0.4. The Cronbach's Alpha of all four factors was higher than 0.6, indicating acceptable reliability. The four extracted factors were respectively labelled as noise, spatial comfort, exercise condition, and technology condition.

\section{Spatial Comfort}

The study of Miller (2009) has shown that the learning space and a comfortable environment have an important influence on learning. The learners' perception of comfort depends on temperature, light, furniture, and air quality, which is consistent with the data of physical environment recorded by the CCEI of ergonomics through on-spot observation (Zandvliet \& Fraser, 2004, 2005). This factor reveals the learners' perception of the comfort related to these environmental factors in the physical space.

\section{Exercise Condition}

In the process of distance education, learners live and study in the same room, and there may not be any sports facilities nearby. Under the influence of COVID-19, the learners are forced to reduce outdoor activities. These factors, when working together, may lead to insufficient exercise of the learners. This factor reveals the learners' perception of the exercise conditions they have in the process of online education and the level of exercise in which they participate; the higher the number of responses, the poorer the exercise conditions.

\section{Noise}

In the interviews, the students mentioned that they might be influenced by noises in the process of learning, including the conversations of their parents, noises made by children, activities of neighbours, outdoor constructions, etc. Studies have shown that noise can lower the willingness of learners to think, as well as their learning motivation and academic performance; noise can also influence the emotions of learners, resulting in feelings such as helplessness (Evans \& Stecker, 2004). This factor is used to indicate the level of noise/silence experienced by learners in the learning environment.

\section{Technology Condition}

In the process of distance education, learners depend fully on such technologies as computers, mobile phones, and Wi-Fi to study and communicate with their teachers, classmates, and friends. Therefore, the stability and performance of the devices is crucial to learners. This factor reveals the learners' perception of the stability and performance of the technological devices they use. 
Table 2. EFA of PEP

\begin{tabular}{|c|c|c|c|c|}
\hline Factors & Items & $\begin{array}{l}\text { Factor } \\
\text { Loadings }\end{array}$ & $\begin{array}{c}\% \text { of } \\
\text { Variance }\end{array}$ & $\begin{array}{l}\text { Cronbach's } \\
\text { Alpha }\end{array}$ \\
\hline \multirow{5}{*}{$\begin{array}{l}\text { Spatial } \\
\text { Comfort } \\
\text { (SC) }\end{array}$} & $\begin{array}{l}\text { 1. I feel comfortable with the light and brightness in the } \\
\text { study room. }\end{array}$ & .812 & 30.16 & .836 \\
\hline & $\begin{array}{l}\text { 2. I feel comfortable with the chair and desk when } \\
\text { studying. }\end{array}$ & .777 & & \\
\hline & 3. The air quality remains good in the study room. & .759 & & \\
\hline & 4. I feel comfortable with the size of the study room. & .730 & & \\
\hline & $\begin{array}{l}\text { 5. I feel comfortable with the temperature and humidity of } \\
\text { the study room. }\end{array}$ & .696 & & \\
\hline \multirow{3}{*}{$\begin{array}{l}\text { Exercise } \\
\text { Condition } \\
\text { (EC) }\end{array}$} & $\begin{array}{l}\text { 1. My involvement in exercise is little during online } \\
\text { learning. }\end{array}$ & .865 & 15.03 & .738 \\
\hline & 2. My walking time is little during online learning. & .802 & & \\
\hline & 3. Lack of exercise spaces during online learning. & .764 & & \\
\hline Noise & 1. The place where I am studying is very quiet. (reverse) & .799 & 9.72 & .678 \\
\hline \multirow[t]{2}{*}{$(\mathrm{NO})$} & 2. Excessive noises often annoy me when studying. & -.789 & & \\
\hline & $\begin{array}{l}\text { 3. I can only hear sounds related to the class when I take } \\
\text { a class (reverse) }\end{array}$ & 693 & & \\
\hline \multirow{3}{*}{$\begin{array}{l}\text { Technology } \\
\text { Condition } \\
\text { (TC) }\end{array}$} & $\begin{array}{l}\text { 1. Electronic devices breaking down often interrupt } \\
\text { learning. (reverse) }\end{array}$ & .789 & 7.39 & .602 \\
\hline & $\begin{array}{l}\text { 2. Some faults, from time to time, happen when I use the } \\
\text { electronic devices during my learning. (reverse) }\end{array}$ & .782 & & \\
\hline & 3. The electronic devices for my learning are very stable. & -.669 & & \\
\hline
\end{tabular}

\section{EFA of PHP}

The EFA results of scale of PHP are as shown in Table 3. A total of three factors were extracted, accounting for $67.038 \%$ of the total variance. All items had a factor loading higher than 0.7 and all four factors had a Cronbach's Alpha higher than 0.6, indicating an acceptable reliability. The three extracted factors were labelled as physical fitness, brain fatigue, and COVID-19 avoidance.

\section{Physical Fitness}

Since learners need to sit in front of the computer and gaze at the monitor for long periods of time, in addition to a lack of exercise, all kinds of discomforts of somatic functions may occur. This situation may also lead to obesity, and some learners worried about skin deterioration and decreased vision due to exposure to monitor radiation caused by long-time use of computers. This factor reveals the learners' perception of their physical health. The higher the number of responses, the poorer the healthy.

\section{Brain Fatigue}

Keeping a fresh brain and energy is helpful for learning. This factor reveals the learners' perception of brain fatigue and their level of energy.

\section{COVID-19 Avoidance}

Since learners are threatened by COVID-19, they may be worried about the possibility of becoming infected by the virus, and the level of such worry may have influence the learners' willingness to 
Table 3. EFA of PHP

\begin{tabular}{|c|c|c|c|c|}
\hline & Items & $\begin{array}{l}\text { Factor } \\
\text { Loadings }\end{array}$ & $\begin{array}{c}\% \text { of } \\
\text { Variance }\end{array}$ & $\begin{array}{c}\text { Cronbach's } \\
\text { Alpha }\end{array}$ \\
\hline \multirow{5}{*}{$\begin{array}{l}\text { Physical } \\
\text { Fitness } \\
(\mathrm{PF})\end{array}$} & $\begin{array}{l}\text { 1. I often feel some parts of my body aching and tiring } \\
\text { during online learning. }\end{array}$ & .819 & 37.551 & .849 \\
\hline & $\begin{array}{l}\text { 2. The muscles and bones didn't get involved in exercise } \\
\text { during online learning. }\end{array}$ & .814 & & \\
\hline & 3. I feel my health is getting worse during online learning. & .746 & & \\
\hline & 4. I feel I will put on weight during online learning. & .738 & & \\
\hline & $\begin{array}{l}\text { 5. I feel that my eyes and skin get worse during online } \\
\text { learning. }\end{array}$ & & & \\
\hline \multirow{3}{*}{$\begin{array}{l}\text { Brain } \\
\text { Fatigue } \\
(\mathrm{BF})\end{array}$} & 1. It is easy to feel sleepy during online learning. & .874 & 15.893 & .858 \\
\hline & $\begin{array}{l}\text { 2. It is easy to feel low energy with online distance } \\
\text { learning. }\end{array}$ & .854 & & \\
\hline & 3. I often feel quite exhausted during online learning. & .835 & & \\
\hline \multirow{3}{*}{$\begin{array}{l}\text { COVID-19 } \\
\text { Avoidance } \\
\text { (CA) }\end{array}$} & $\begin{array}{l}\text { 1. It is very safe taking online learning at home in terms } \\
\text { of avoiding getting sick. }\end{array}$ & .779 & 13.594 & .632 \\
\hline & $\begin{array}{l}\text { 2. Online learning at home will be able to prevent me } \\
\text { from contracting the virus. }\end{array}$ & .768 & & \\
\hline & 3. Online learning at home avoids infectious diseases. & .722 & & \\
\hline
\end{tabular}

participate in outdoor activities, as well as their diminish their physical conditions and mental health. This factor reveals the learners' worry and avoidance of the viral infection.

\section{EFA of MHP}

This study developed a scale of MHP on the basis of a reference to AEQ and the scale of isolation, as well as student interviews. The EFA results are as shown in Table 4. The results of factor extraction were as expected. There was a total of four factors: enjoyment, boredom, anxiety, and isolation, accounting for $78.696 \%$ of the total variance. All items had a factor loading higher than 0.7 and all four factors had a Cronbach's Alpha higher than 0.8, indicating an excellent level of reliability.

\section{CONFIRMATORY FACTOR ANALYSIS (CFA)}

In order to verify the reliability of the questionnaire and confirm the goodness of fit indices of the measurement models of the three scales, IBM's data analysis software (AMOS version 24.0) was used to conduct a CFA to the measurement model of sample 2 based on the result of maximum likelihood estimation.

\section{CFA of PEP}

The AMOS output results obtained were: $\mathrm{CMIN}=95.935, \mathrm{df}=70, \mathrm{p}=0.022>.05, \mathrm{CMIN} / \mathrm{df}=$ $1.371<2, \mathrm{CFI}=0.974, \mathrm{GFI}=0.941, \mathrm{NFI}=0.911, \mathrm{TLI}=0.966, \mathrm{AGFI}=0.911, \mathrm{PGFI}=0.627, \mathrm{SRMR}$ $=.0587$, RFI $=0.885$, and RMSEA $=0.043$. These adaption indices indicated a good adaption between the measurement model of PEP and the data.

As shown in Table 5, the factor loadings of TC3 is $0.361<0.55$, and the average variance extracted (AVE) of the construct of technology condition is $0.352<0.5$, which means the three items are a lessthan-effective measure of the latent construct of technology condition, so the researchers removed 
Table 4. EFA of MHP

\begin{tabular}{|c|c|c|c|c|}
\hline Factors & Items & $\begin{array}{l}\text { Factor } \\
\text { Loadings }\end{array}$ & $\begin{array}{c}\% \text { of } \\
\text { Variance }\end{array}$ & $\begin{array}{c}\text { Cronbach's } \\
\text { Alpha }\end{array}$ \\
\hline \multirow{3}{*}{$\begin{array}{l}\text { Anxiety } \\
(\mathrm{AX})\end{array}$} & 1. Be worried about bad tests results and scores. & .924 & 36.159 & .906 \\
\hline & 2. Be worried about not doing well in learning. & .902 & & \\
\hline & 3. Be worried about not doing well in homework. & .886 & & \\
\hline \multirow{3}{*}{$\begin{array}{l}\text { Isolation } \\
\text { (IS) }\end{array}$} & 1. Feel isolated from the world. & .900 & 19.893 & .867 \\
\hline & 2. I often feel lonely. & .848 & & \\
\hline & 3. I feel idle, apart from online learning. & .807 & & \\
\hline \multirow{3}{*}{$\begin{array}{l}\text { Enjoyment } \\
(\mathrm{EN})\end{array}$} & $\begin{array}{l}\text { 1. Online learning provides a pleasant learning } \\
\text { experience. }\end{array}$ & .876 & 12.812 & .835 \\
\hline & 2. Online learning presents an interesting way to learn. & .871 & & \\
\hline & $\begin{array}{l}\text { 3. Online learning encourages me to engage in in-depth } \\
\text { study. }\end{array}$ & .783 & & \\
\hline \multirow{3}{*}{$\begin{array}{l}\text { Boredom } \\
\text { (BO) }\end{array}$} & $\begin{array}{l}\text { 1. Online learning makes me think learning is very } \\
\text { boring. }\end{array}$ & .834 & 9.831 & .807 \\
\hline & 2. Online learning makes me fed up with studying. & .815 & & \\
\hline & $\begin{array}{l}\text { 3. I'd rather do other things than online learning, if } \\
\text { possible. }\end{array}$ & .769 & & \\
\hline
\end{tabular}

this structure from the physical environment scale. In addition to this, all other measured variables reached a significant level in the corresponding potential structure $(\mathrm{p}<0.001)$, with a factor loading of $>0.55$, the average variance extracted as (AVE) $>0.5$, and composite reliability $(\mathrm{CR})>0.6$. These evaluation indices indicated a good convergent validity of the measurement model of PEP except for the construct of technology condition.

For the discriminant validity of the measurement model, Table 6 shows that the square root of the average variance extracted for each latent construct was higher than the inter-construct correlation, providing sufficient evidence of discriminant validity for the constructs.

\section{CFA of PHP}

The AMOS output results obtained were: $\mathrm{CMIN}=56.711, \mathrm{df}=41, \mathrm{p}=0.052>0.05, \mathrm{CMIN} / \mathrm{df}=$ $1.38<2, \mathrm{CFI}=0.981, \mathrm{GFI}=0.954, \mathrm{TLI}=0.975, \mathrm{NFI}=0.936, \mathrm{AGFI}=0.926, \mathrm{PGFI}=0.593, \mathrm{SRMR}$ $=0.0495, \mathrm{RFI}=0.914, \mathrm{RMSEA}=0.043$. These adaption indices indicated a good adaption between the measurement model of PEP and the data.

As shown in Table 7, all measured variables reached a significant level in the corresponding potential structure $(\mathrm{p}<0.001)$, with a factor loading of $>0.55$, an average variance extracted from every structure of $(\mathrm{AVE})>0.5$, and a composite reliability of $(\mathrm{CR})>0.6$. These evaluation indices indicated a good convergent validity of the measurement model of PEP.

For the discriminant validity of the measurement model, Table 8 shows that the square root of the average variance extracted for each latent construct was higher than the inter-construct correlation, providing sufficient evidence of discriminant validity for the constructs.

\section{CFA of MHP}

The AMOS output results obtained were: $\mathrm{CMIN}=59.737, \mathrm{~d} f=50, \mathrm{p}=0.163>0.05, \mathrm{CMIN} / \mathrm{df}=$ $1.19<2, \mathrm{CFI}=0.993, \mathrm{GFI}=0.954, \mathrm{TLI}=0.991, \mathrm{NFI}=0.962, \mathrm{AGFI}=0.929, \mathrm{PGFI}=0.612, \mathrm{SRMR}$ 
Table 5. CFA of PEP

\begin{tabular}{|c|c|c|c|c|}
\hline Factors & Items & Estimate & Composite Reliability & AVE \\
\hline \multirow{3}{*}{ Noise } & NO1 & .576 & .772 & .536 \\
\hline & $\mathrm{NO} 2$ & .782 & & \\
\hline & NO3 & .815 & & \\
\hline \multirow{5}{*}{ Space Comfort } & $\mathrm{SC} 1$ & .686 & .850 & .532 \\
\hline & $\mathrm{SC} 2$ & .760 & & \\
\hline & SC3 & .842 & & \\
\hline & $\mathrm{SC} 4$ & .665 & & \\
\hline & SC5 & .680 & & \\
\hline \multirow{3}{*}{ Exercise Condition } & $\mathrm{EC} 1$ & .713 & .845 & .645 \\
\hline & $\mathrm{EC} 2$ & .842 & & \\
\hline & EC3 & .848 & & \\
\hline \multirow{3}{*}{ Technology Condition } & $\mathrm{TC} 1$ & .632 & .603 & .352 \\
\hline & $\mathrm{TC} 2$ & .727 & & \\
\hline & TC3 & .361 & & \\
\hline
\end{tabular}

Table 6. The discriminant validity of the measurement model

\begin{tabular}{|l|l|l|l|l|}
\hline \multicolumn{1}{|c|}{ Factors } & \multicolumn{1}{|c|}{ Mean (SD) } & \multicolumn{1}{c|}{ Noise } & \multicolumn{1}{c|}{ Space Comfort } & Exercise Condition \\
\hline Noise & $2.945(.814)$ & .732 & & \\
\hline Space Comfort & $3.813(.707)$ & .509 & .729 & \\
\hline Exercise Condition & $3.874(.871)$ & -.179 & -.133 & .739 \\
\hline
\end{tabular}

Table 7. CFA of PHP

\begin{tabular}{|l|l|l|l|l|}
\hline \multicolumn{1}{|c|}{ Factors } & \multicolumn{1}{|c|}{ Items } & Estimate & Composite Reliability & AVE \\
\hline \multirow{5}{*}{ Physical Fitness } & PF1 & .655 & .855 & .547 \\
\cline { 2 - 5 } & PF2 & .574 & & \\
\cline { 2 - 5 } & PF3 & .702 & & \\
\cline { 2 - 5 } & PF4 & .872 & & \\
\cline { 2 - 5 } & PF5 & .849 & .854 & .665 \\
\hline \multirow{5}{*}{ Brain Fatigue } & BF1 & .652 & & \\
\cline { 2 - 5 } & BF2 & .888 & .762 & .517 \\
\hline & BF3 & .884 & & \\
\hline \multirow{5}{*}{ COVID-19 Avoidance } & CA1 & .744 & & \\
\cline { 2 - 5 } & CA2 & .722 & & \\
\cline { 2 - 5 } & CA3 & .689 & & \\
\hline
\end{tabular}


Table 8. The discriminant validity of the measurement model

\begin{tabular}{|l|l|l|l|l|}
\hline \multicolumn{1}{|c|}{ Factors } & \multicolumn{1}{|c|}{ Mean (SD) } & \multicolumn{1}{|c|}{ Physical Fitness } & \multicolumn{1}{c|}{ Brain Fatigue } & $\begin{array}{c}\text { COVID-19 } \\
\text { Avoidance }\end{array}$ \\
\hline Physical Fitness & $3.592(.911)$ & .739 & & \\
\hline Brain Fatigue & $3.299(.951)$ & .488 & .815 & \\
\hline COVID-19 Avoidance & $3.750(.657)$ & .005 & -.136 & .719 \\
\hline
\end{tabular}

$=0.038, \mathrm{RFI}=0.949$, and RMSEA $=0.031$. These adaption indices indicated a good adaption between the measurement model of PEP and the data.

As shown in Table 9, all measured variables reached a significant level in the corresponding potential structure $(\mathrm{p}<0.001)$, with a factor loading of $>0.55$, an average variance extracted from every structure of $(\mathrm{AVE})>0.5$, and a composite reliability of $(\mathrm{CR})>0.6$. These evaluation indices indicated a good convergent validity of the measurement model of PEP.

For the discriminant validity of the measurement model, Table 10 shows that the square root of the average variance extracted for each latent construct was higher than the inter-construct correlation, providing sufficient evidence of discriminant validity for the constructs.

\section{Table 9. CFA of MHP}

\begin{tabular}{|l|l|l|l|l|}
\hline \multicolumn{1}{|c|}{ Factors } & \multicolumn{1}{|c|}{ Items } & \multicolumn{1}{c|}{ Estimate } & Composite Reliability & \multicolumn{1}{c|}{ AVE } \\
\hline \multirow{5}{*}{ Enjoyment } & EN1 & .678 & .884 & .721 \\
\cline { 2 - 6 } & $\mathrm{EN} 2$ & .930 & & \\
\cline { 2 - 6 } & $\mathrm{EN} 3$ & .916 & & \\
\hline \multirow{5}{*}{ Boredom } & $\mathrm{BO} 1$ & .876 & .896 & .741 \\
\cline { 2 - 6 } & $\mathrm{BO} 2$ & .910 & & \\
\cline { 2 - 6 } & $\mathrm{BO} 3$ & .793 & .899 & .748 \\
\hline \multirow{5}{*}{ Isolation } & $\mathrm{AX} 1$ & .877 & & \\
\cline { 2 - 6 } & $\mathrm{AX} 2$ & .886 & .825 & \\
\cline { 2 - 6 } & $\mathrm{AX} 3$ & .830 & & \\
\hline & $\mathrm{IS} 1$ & .804 & & \\
\cline { 2 - 6 } & IS2 & .834 & & \\
\cline { 2 - 6 } & IS3 & .702 & & \\
\hline
\end{tabular}

Table 10. The discriminant validity of the measurement model

\begin{tabular}{|l|l|l|l|l|l|}
\hline \multicolumn{1}{|c|}{ Factors } & \multicolumn{1}{c|}{ Mean (SD) } & \multicolumn{1}{c|}{ Enjoy } & \multicolumn{1}{c|}{ Boredom } & \multicolumn{1}{c|}{ Anxiety } & Isolation \\
\hline Enjoyment & $3.237(.936)$ & .849 & & & \\
\hline Boredom & $2.564(.996)$ & -.537 & .861 & & \\
\hline Anxiety & $3.857(.892)$ & -.130 & .292 & .865 & \\
\hline Isolation & $2.852(1.129)$ & -.284 & .544 & .488 & .782 \\
\hline
\end{tabular}


Table 11. The influence of PEP on PHP

\begin{tabular}{|c|c|c|c|c|c|c|}
\hline & \multicolumn{2}{|c|}{ Physical Fitness } & \multicolumn{2}{|c|}{ Brain Fatigue } & \multicolumn{2}{|c|}{ COVID-19 Avoidance } \\
\hline & Beta & Sig. & Beta & Sig. & Beta & Sig. \\
\hline Noise & .080 & .195 & .125 & .090 & -.033 & .676 \\
\hline Space Comfort & -.123 & .045 & -.137 & .062 & .120 & .125 \\
\hline Exercise Condition & .582 & .000 & .267 & .000 & .045 & .522 \\
\hline $\mathrm{R} 2$ & \multicolumn{2}{|l|}{$39.6 \%$} & \multicolumn{2}{|l|}{$13.7 \%$} & \multicolumn{2}{|l|}{$1.9 \%$} \\
\hline F Change & \multicolumn{2}{|l|}{43.94} & \multicolumn{2}{|l|}{10.66} & \multicolumn{2}{|l|}{1.331} \\
\hline $\mathrm{p}$ & \multicolumn{2}{|l|}{.000} & \multicolumn{2}{|l|}{.000} & \multicolumn{2}{|l|}{.265} \\
\hline
\end{tabular}

\section{INFLUENCE OF PLE ON HEALTH}

In order to analyse the influence of physical environment perception (PEP) on PHP and MHP, IBM's data analysis software (SPSS version 24.0) was used for multivariate regression analysis.

\section{Influence of PLE on Physical Health}

In order to evaluate the extent to which the four factors of the PEP can predict the learners' PHP, the three factors of PHP were used as the dependent variables for the multivariate regression analysis. The results are as shown in Table 11; exercise condition and space comfort can significantly predict PHP. A certain proportion of brain fatigue can be explained with exercise condition, but the proportion of explanation is low. While the learners' worries and avoidance of the virus were not correlated with their PEP.

The results indicate that exercise condition has a significant influence on physical fitness and brain fatigue. Meanwhile, the descriptive data show that when the students participate in online education, they have shown low levels of exercise condition $(M=2.13)$, physical fitness perception $(M=2.41)$, and high level of brain fatigue $(M=3.29)$. Thus, it follows that the insufficiency of exercise condition has led to insufficient exercise in the process of learning, and then causes terrible levels of physical health. However, spatial comfort and noise are not significantly correlated with PHP. Finally, PEP is not related to the learners' avoidance and worries about the virus, indicating that there might be no risk of COVID-19 infection in the physical environment of the learners. Interviews with the learners have also confirmed that among all students interviewed, none had encountered patients infected with the virus in their living environment, and that they learned about the virus through the media, such as TV and social media, rather than in a real physical environment. The learner's information environment is a subject that needs attention.

\section{Influence of PLE on Mental Health}

In order to evaluate the influence of PEP on MHP, the four factors of MHP were used as dependent variables to conduct a multivariate regression analysis. The results are as shown in Table 12; spatial comfort can significantly and positively predict the emotion of enjoyment, while noise only has a slightly negative influence on the emotion of enjoyment. Spatial comfort and noise have significant impacts on emotion of boredom. In terms of learning anxiety perception, spatial comfort and exercise condition can significantly predict the level of learning anxiety. In terms of the isolation of the learners, the higher the spatial comfort, the lower the loneliness; the worse the exercise condition, the higher the loneliness.

In general, the three factors of physical environment all have significant influence on MHP, but they show relatively low explanation proportion of the variance of the four mental health factors 
Table 12. The influence of PEP on MHP

\begin{tabular}{|c|c|c|c|c|c|c|c|c|}
\hline & \multicolumn{2}{|c|}{ Enjoyment } & \multicolumn{2}{|c|}{ Boredom } & \multicolumn{2}{|c|}{ Anxiety } & \multicolumn{2}{|c|}{ Isolation } \\
\hline & Beta & Sig. & Beta & Sig. & Beta & Sig. & Beta & Sig. \\
\hline Noise & -.167 & .052 & .167 & .028 & -.023 & .756 & .042 & .553 \\
\hline Space Comfort & .168 & .005 & -.157 & .037 & -.171 & .019 & -.288 & .000 \\
\hline Exercise Condition & -.088 & .160 & .101 & .140 & .338 & .000 & .274 & .000 \\
\hline $\mathrm{R} 2$ & \multicolumn{2}{|l|}{$11 \%$} & \multicolumn{2}{|l|}{$9.3 \%$} & \multicolumn{2}{|l|}{$14.8 \%$} & \multicolumn{2}{|l|}{$18.8 \%$} \\
\hline $\mathrm{F}$ & \multicolumn{2}{|l|}{8.264} & \multicolumn{2}{|l|}{6.896} & \multicolumn{2}{|l|}{11.662} & \multicolumn{2}{|l|}{15.511} \\
\hline $\mathrm{p}$ & \multicolumn{2}{|l|}{.000} & \multicolumn{2}{|l|}{.000} & \multicolumn{2}{|l|}{.000} & \multicolumn{2}{|l|}{.000} \\
\hline
\end{tabular}

(with the highest value of R2 being $18.8 \%$ and the lowest value being 9.3\%). Spatial comfort is the factor of physical environment that deserves the highest attention and should be improved, and all factors such as temperature, humidity, light, desk, and chair, as well as the size of the learning space have an influence on several mental health factors of the learners. The learners have shown a high acceptance of noise, which is probably because most learners have an independent space for study in the process of distance education, and the noises are mainly from their family members, which is not necessarily negative, as they can also make the learners feel the care and companionship of their family members. For example, in the interview, some students mentioned that the noise of their parents cooking would disturb them during their study and that parents often asked them to eat during the class time. At the same time, they mentioned that one of the advantages of distance education was that "I could eat the tasty food prepared by my parents." It is worth noting that the improvement of exercise condition can reduce the loneliness and learning anxiety of learners, so for some learners, getting them involved in physical exercise may reduce their negative emotions.

\section{INFLUENCE OF PEP, PHP, AND MHP ON LEARNING SATISFACTION}

In order to analyse the influence of PEP, PHP, and MHP on learning satisfaction, IBM's data analysis software (SPSS version 24.0) was used for hierarchical multivariate regression analysis. Descriptive statistics of learning satisfaction are shown in the Table 13. With learning satisfaction as the dependent variable, and on the basis of the literature review, PEP, PHP, and MHP were put into the regression model one by one. The results are as shown in Table 14; all three sets of factors show a certain level of explanatory power of the learning satisfaction, among which MHP shows the highest explanatory power (Incremental R2 $=0.671$ ).

Specifically speaking, in the three models, spatial comfort remains the explanatory power for learning satisfaction, while noise and physical exercise conditions are not directly correlated to learning satisfaction. In model 2, brain fatigue and virus avoidance show a significant prediction level of the learning satisfaction, but in model 3, due to the introduction of MHP, the prediction level of brain fatigue and virus avoidance no long showed a significant prediction level of the learning satisfaction. All four factors of MHP showed a satisfactory prediction level of the learning satisfaction. This result suggested that if learners can be helped to control brain fatigue and the threat of the virus, they will be able to maintain better mental health and, thus, improve their learning satisfaction.

\section{DISCUSSION AND CONCLUSION}

In order to study the influence of the PEP of full-time college students receiving distance education due to the influence of COVID-19 on their perception of physical health, mental health, and the 
Table 13. Descriptive statistics for learning satisfaction

\begin{tabular}{|l|l|l|l|}
\hline \multicolumn{1}{|c|}{ Items } & \multicolumn{1}{|c|}{ Mean } & \multicolumn{1}{c|}{ SD } & \multicolumn{1}{c|}{$\begin{array}{c}\text { Cronbach's } \\
\text { Alpha }\end{array}$} \\
\hline 1. I am satisfied with the effect of online learning at home. & 3.36 & .968 & .881 \\
\hline 2. Online learning at home makes my major courses more effective. & 2.97 & .967 & \\
\hline 3. This method, online learning, disappoints me severely. (reverse) & 3.26 & 1.102 & \\
\hline 4. It is more difficult to learn through online learning. (reverse) & 3.18 & 1.147 & \\
\hline $\begin{array}{l}\text { 5. Online learning at home has greatly reduced my learning performance. } \\
\text { (reverse) }\end{array}$ & 2.92 & 1.061 & \\
\hline
\end{tabular}

Table 14. Prediction of PEP, PHP, and MHP on learning satisfaction

\begin{tabular}{|c|c|c|c|c|c|c|}
\hline & \multicolumn{2}{|c|}{ Model 1} & \multicolumn{2}{|c|}{ Model 2} & \multicolumn{2}{|c|}{ Model 3} \\
\hline & Beta & Sig. & Beta & Sig. & Beta & Sig. \\
\hline Noise & -.041 & .579 & .009 & .897 & .087 & .069 \\
\hline Space Comfort & .329 & .000 & .259 & .000 & .127 & .010 \\
\hline Exercise Condition & -.115 & .083 & -.006 & .937 & .001 & .991 \\
\hline Physical Fitness & & & -.052 & .529 & .103 & .085 \\
\hline Brain Fatigue & & & -.322 & .000 & -.088 & .088 \\
\hline COVID-19 Avoidance & & & .157 & .011 & -.021 & .659 \\
\hline Enjoyment & & & & & .420 & .000 \\
\hline Boredom & & & & & -.362 & .000 \\
\hline Anxiety & & & & & -.102 & .043 \\
\hline Isolation & & & & & -.146 & .007 \\
\hline Incremental $\mathrm{R}^{2}$ & \multicolumn{2}{|l|}{.143} & \multicolumn{2}{|l|}{.133} & \multicolumn{2}{|l|}{.391} \\
\hline $\mathrm{R}^{2}$ & \multicolumn{2}{|l|}{.143} & \multicolumn{2}{|l|}{.276} & \multicolumn{2}{|l|}{.667} \\
\hline $\mathrm{F}$ & \multicolumn{2}{|l|}{11.149} & \multicolumn{2}{|l|}{12.573} & \multicolumn{2}{|l|}{38.822} \\
\hline $\mathrm{p}$ & \multicolumn{2}{|l|}{.000} & \multicolumn{2}{|l|}{.000} & \multicolumn{2}{|l|}{.000} \\
\hline
\end{tabular}

influence of these factors on their learning satisfaction, this paper developed three scales based on a literature review and student interviews, respectively, about the PEP, PHP, and MHP of the learners receiving distance education due to the influence of COVID-19, and verified the reliability and validity of these scales.

Existing studies on the PLE primarily focus on the formal environment on campus, which mainly adopts such methods as on-spot investigation and interviews with teachers and students. Considering the complicated learning environment and the dispersing feature of learners in distance education, this study referred to the CCEI used for the physical environment study in formal education, and developed a scale to measure the PEP of the learners on the basis of interviews with the learners and through the method of factor analysis with consideration given to the particular influence of COVID-19. Similarly, on the basis of a literature review and interviews with learners, scales were developed to measure the PHP and MHP of learners receiving distance education under the influence of COVID-19. The results have shown that the learners' perception of the physical environment can be identified in three aspects, and their perception of physical health can be divided into three categories. In terms of 
the learners' perception of mental health, this study referred to the AEQ learning emotion scale and the scale of isolation and generated the four factors. In particular, the EFA of physical environment indicated that technical conditions are also an effective environmental factor, but the CFA showed that the construct of technical conditions does not meet the statistical criteria, so it was deleted. This may have been due to the problematic description of the items. Some studies have shown that technical support has a significant impact on learning satisfaction in distance learning (Amoozegar, Daud, Mahmud, \& Jalil, 2017). In the future research, researchers can continuously improve the technical condition scale and explore the influence of technological factors.

In terms of the influence of PEP on learners, the noises in the physical environment did not have significant influence on the physical health, mental health, or learning satisfaction of the learners, which may be because the learners are in a relatively isolated and independent space when in the process of online learning, thus they are influenced by noise to a limited extent. Most of the noise came from family members. Although such noise would disturb the learners, it did not cause excessive aversion for learners, because the noise meant the care and companionship of the parents. However, there were a few learners who made it clear that they did not like it when their parents disturbed them. Therefore, it is necessary for teachers to communicate with learners' parents so that they will not disturb the learners during class times. In addition, a small number of students stated in the interviews that they disturbed by noises created by interior decorating being performed by neighbours and also noise from outdoor construction. Additional research may be needed to further subdivide the noise disturbing the learners to identify the influence of different sources of noise on learners. There is almost no correlation between the learners' PHP and the comfort level of the physical environment, including temperature, humidity, air quality, light, brightness, adaption of desk and chair, and the size of the learning space, but the PEP had a significant influence on the mental health and the emotions of the learners. Better exercise conditions and opportunities cannot only improve the level of physical health, but also help reduce negative emotions such as anxiety and isolation of the learners. Compared with learning on campus, learners receiving distance education have an obvious lack of physical exercise conditions. Some students said in the interviews that they often got up when the class was about to begin, and that they would spend too much time sitting and rarely did physical exercise. Most of the learners interviewed said they would cut down on outdoor physical exercise for worrying about getting the virus. Therefore, in the physical environment setting of distance education, one of the challenges is to increase physical exercise conditions for the students, especially under specific conditions such as the COVID-19 outbreak. It is necessary for education institutions to arrange some indoor physical exercise between classes so that the learners can complete a certain amount of physical exercise every day, and to arrange some outdoor physical exercise that learners enjoy, if conditions permit. This can help students maintain their physical and mental health. Education institutions can also communicate with learners' families to ensure that learners have a comfortable learning environment as far as possible, which is necessary for the reduction of anxiety and loneliness of the learners.

There is no consistent conclusion on whether PLE and physical activity affect learning satisfaction. The results of this study have shown that when learners participate in distance learning at home, physical exercise conditions and noise in the physical environment have no direct impact on learning satisfaction. In contrast, environmental comfort has a significant impact on learning satisfaction. Therefore, creating a more comfortable environment for students in terms of temperature, humidity, space, light, desk, and chair, etc. will help to improve their learning satisfaction. Numerous studies have shown that higher learning satisfaction can improve academic performance. However, the results of the interviews showed that the improvement of learners' satisfaction might also be because that the comfortable environment suits their lazy habits. Some learners said that online classes at home could free them from walking around the campus, thus helping them avoid being exposed to the sun and the wind, and much time could be saved in this way, which made them prefer online learning. Therefore, learners' motivations in learning and their lazy habits may be a controlling variable affecting the 
relationship between the learning environment, physical exercise conditions, and learning satisfaction, which can be further studied in the future.

Whether learners prefer a comfortable, physical exercise-free learning environment because it saves time or because they are lazy, it is not conducive for learners to participate in physical exercise and, thus, improve their physical and mental health. The results of this study show that the four factors of mental health have a significant impact on the improvement of learning satisfaction. Therefore, improving the comfort level of the learning environment and providing good physical exercise conditions can indirectly affect learning satisfaction by guaranteeing the learners' mental health. In addition, controlling the degree of brain fatigue and the threat of the virus also helps reduce the psychological burden of the learners, thus improving their learning satisfaction. Generally speaking, for the purpose of protecting the learners' mental health and improving their learning satisfaction, educators should try their best to create conditions to protect learners' positive emotions, and avoid negative emotions such as boredom, anxiety, and loneliness. These conditions include a comfortable learning space, good physical exercise conditions, and protection from the virus. In addition, this study has found that although the physical environment can affect learners' perception of mental health, its explanation degree of the changes in mental health is not high. Previous studies have shown that learners' mental health is significantly affected by psychosocial environment and interaction (Wei \& Chen, 2012). The objective of this study was to analyse the impact of the PLE, but it did not involve the social psychological environment and learners" interaction behaviours, which should be the focus in future research.

The research subjects of this study were students from a university located in an economically developed area in South China, considering differences in economic conditions, information technology literacy, academic performance, and the influence of China's unique cultural and educational system, this study may have limitations in the representativeness of the samples and some deficiencies in the adaptability of the conclusions. In future studies, the researchers hope that the conclusions of this study can be verified in more general samples in the future.

Another limitation of this study is that the investigation only focused on distance learning during the epidemic period, and no comparison was made with on-campus learning or distance learning under non-epidemic conditions. Therefore, it is impossible to determine whether there are differences in learners' satisfaction under several conditions and what are the reasons for such differences. In the future, comparative studies can be conducted to gain a deeper understanding of distance learning under the epidemic. 


\section{REFERENCES}

Allen, I. E., \& Seaman, J. (2017). Digital Compass Learning: Distance Education Enrollment Report 2017. Babson Survey Research Group.

Alphonse, A., Orellana, A., \& Kanzki-Veloso, E. (2019). How Online Students Describe Their Physical Learning Environment. Quarterly Review of Distance Education, 20(2), 29-74.

Amoozegar, A., Daud, S. M., Mahmud, R., \& Jalil, H. A. (2017). Exploring learner to institutional factors and learner characteristics as a success factor in distance learning. International Journal of Innovation and Research in Educational Sciences, 4(6), 647-656.

Arbaugh, J. B. (2000). Virtual classroom characteristics and student satisfaction with internet-based MBA courses. Journal of Management Education, 24(1), 32-54. doi:10.1177/105256290002400104

Chism, N. V. N. (2006). Challenging traditional assumptions and rethinking learning spaces. Learning Spaces, 2-1.

Choi, H. H., Van Merriënboer, J. J., \& Paas, F. (2014). Effects of the physical environment on cognitive load and learning: Towards a new model of cognitive load. Educational Psychology Review, 26(2), 225-244. doi:10.1007/ s10648-014-9262-6

Christopher, A. A., Dzakiria, H., \& Mohamed, A. H. (2012). Teaching English through sports: A case study. Asian EFL Journal, 59(4), 20-29.

Cleveland, B., \& Fisher, K. (2014). The evaluation of physical learning environments: A critical review of the literature. Learning Environments Research, 17(1), 1-28. doi:10.1007/s10984-013-9149-3

Eom, S. B., Wen, H. J., \& Ashill, N. (2006). The determinants of students' perceived learning outcomes and satisfaction in university online education: An empirical investigation. Decision Sciences Journal of Innovative Education, 4(2), 215-235. doi:10.1111/j.1540-4609.2006.00114.x

Erichsen, E. A., \& Bolliger, D. U. (2011). Towards understanding international graduate student isolation in traditional and online environments. Educational Technology Research and Development, 59(3), 309-326. doi:10.1007/s11423-010-9161-6

Evans, G. W., \& Stecker, R. (2004). Motivational consequences of environmental stress. Journal of Environmental Psychology, 24(2), 143-165. doi:10.1016/S0272-4944(03)00076-8

Fedewa, A. L., \& Ahn, S. (2011). The effects of physical activity and physical fitness on children's achievement and cognitive outcomes: A meta-analysis. Research Quarterly for Exercise and Sport, 82(3), 521-535. doi:10. 1080/02701367.2011.10599785 PMID:21957711

Garrison, D. R., Anderson, T., \& Archer, W. (2001). Critical thinking, cognitive presence, and computer conferencing in distance education. American Journal of Distance Education, 15(1), 7-23. doi:10.1080/08923640109527071

Gijselaers, H. J., Kirschner, P. A., Verboon, P., \& de Groot, R. H. (2016). Sedentary behavior and not physical activity predicts study progress in distance education. Learning and Individual Differences, 49, 224-229. doi:10.1016/j.lindif.2016.06.021

Harvey, S. P., Lambourne, K., Greene, J. L., Gibson, C. A., Lee, J., \& Donnelly, J. E. (2018). The effects of physical activity on learning behaviors in elementary school children: A randomized controlled trial. Contemporary School Psychology, 22(3), 303-312. doi:10.1007/s40688-017-0143-0 PMID:30956895

Higgins, S., Hall, E., Wall, K., Woolner, P., \& McCaughey, C. (2005). The impact of school environments: A literature review. Design Council.

Hunley, S., \& Schaller, M. (2009). Assessment: The key to creating spaces that promote learning. EDUCAUSE Review, 44(2), 26.

Jones, D., Hoelscher, D. M., Kelder, S. H., Hergenroeder, A., \& Sharma, S. V. (2008). Increasing physical activity and decreasing sedentary activity in adolescent girls-The Incorporating More Physical Activity and Calcium in Teens (IMPACT) study. The International Journal of Behavioral Nutrition and Physical Activity, 5(1), 42. doi:10.1186/1479-5868-5-42 PMID:18718012 
Júnior, I. F. F., Cardoso, J. R., Christofaro, D. G. D., Codogno, J. S., de Moraes, A. C. F., \& Fernandes, R. A. (2013). The relationship between visceral fat thickness and bone mineral density in sedentary obese children and adolescents. BMC Pediatrics, 13(1), 1-5. doi:10.1186/1471-2431-13-37 PMID:23510224

Kaiser, H. F. (1974). An index of factorial simplicity. Psychometrika, 39(1), 31-36. doi:10.1007/BF02291575

Laurillard, D. (2000). New technologies, students and the curriculum. In P. Scott (Ed.), Higher education reformed (Vol. 133). Academic Press.

Leaman, A., Stevenson, F., \& Bordass, B. (2010). Building evaluation: Practice and principles. Building Research and Information, 38(5), 564-577. doi:10.1080/09613218.2010.495217

Lichtenfeld, S., Pekrun, R., Stupnisky, R. H., Reiss, K., \& Murayama, K. (2012). Measuring students' emotions in the early years: The achievement emotions questionnaire-elementary school (AEQ-ES). Learning and Individual Differences, 22(2), 190-201. doi:10.1016/j.lindif.2011.04.009

Liu, F., Sulpizio, S., Kornpetpanee, S., \& Job, R. (2017). It takes biking to learn: Physical activity improves learning a second language. PLoS One, 12(5), e0177624. doi:10.1371/journal.pone.0177624 PMID:28542333

Liu, C. J., Zandvliet, D. B., \& Hou, I. L. (2012). The learning environment associated with information technology education in Taiwan: Combining psychosocial and physical aspects. Learning Environments Research, 15(3), 379-402. doi:10.1007/s10984-012-9120-8

Logaraj, M., Madhupriya, V., \& Hegde, S. (2014). Computer vision syndrome and associated factors among medical and engineering students in Chennai. Annals of Medical and Health Sciences Research, 4(2), 179-185. doi:10.4103/2141-9248.129028 PMID:24761234

MacIntyre, P. D., \& Vincze, L. (2017). Positive and negative emotions underlie motivation for L2 learning. Studies in Second Language Learning and Teaching, 7(1), 61-88. doi:10.14746/ssllt.2017.7.1.4

Malina, R. M. (2001). Physical activity and fitness: Pathways from childhood to adulthood. American Journal of Human Biology: The Official Journal of the Human Biology Association, 13(2), 162-172. doi:10.1002/15206300(200102/03)13:2<162::AID-AJHB1025>3.0.CO;2-T PMID:11460860

Miller, H. (2009). Adaptable spaces and their impact on learning. Research Summary, Herman Miller Inc. http:// www. hermanmiller. com/research/research-summaries/adaptable-spaces-and-their-impact-on-learning. html

Morgan, C. K., \& Tam, M. (1999). Unravelling the complexities of distance education student attrition. Distance Education, 20(1), 96-108. doi:10.1080/0158791990200108

Penedo, F. J., \& Dahn, J. R. (2005). Exercise and well-being: A review of mental and physical health benefits associated with physical activity. Current Opinion in Psychiatry, 18(2), 189-193. doi:10.1097/00001504200503000-00013 PMID:16639173

Pekrun, R. (2006). The control-value theory of achievement emotions: Assumptions, corollaries, and implications for educational research and practice. Educational Psychology Review, 18(4), 315-341. doi:10.1007/s10648006-9029-9

Pishghadam, R., Zabetipour, M., \& Aminzadeh, A. (2016). Examining emotions in English language learning classes: A case of EFL emotions. Issues in Educational Research, 26(3), 508.

Preiser, W. F. E. (1995). Post-occupancy evaluation: How to make buildings work better. Facilities, 13(11), 19-28. doi:10.1108/02632779510097787

Russell, D., Peplau, L. A., \& Ferguson, M. L. (1978). Developing a measure of loneliness. Journal of Personality Assessment, 42(3), 290-294. doi:10.1207/s15327752jpa4203_11 PMID:660402

Sahin, I. (2007). Predicting Student Satisfaction in Distance Education and Learning Environments. Online submission.

Salinas, J. J., Messias, D. K. H., Morales-Campos, D., \& Parra-Medina, D. (2014). English language proficiency and physical activity among Mexican-origin women in South Texas and South Carolina. Journal of Health Care for the Poor and Underserved, 25(1), 357-375. doi:10.1353/hpu.2014.0033 PMID:24509031 
Shadiev, R., Hwang, W. Y., \& Liu, T. Y. (2018). A study of the use of wearable devices for healthy and enjoyable English as a Foreign language learning in authentic contexts. Journal of Educational Technology \& Society, 21(4), 217-231.

Sharma, S. (1995). Applied multivariate techniques. John Wiley.

Tanner, C. K. (2008). Explaining relationships among student outcomes and the school's physical environment. Journal of Advanced Academics, 19(3), 444-471. doi:10.4219/jaa-2008-812

Toulmin, S. (1978). Mind in society: Development of higher psychological processes-Vygotsky, LS. Academic Press.

Tremblay, M. S., LeBlanc, A. G., Kho, M. E., Saunders, T. J., Larouche, R., Colley, R. C., Goldfield, G., \& Gorber, S. C. (2011). Systematic review of sedentary behaviour and health indicators in school-aged children and youth. The International Journal of Behavioral Nutrition and Physical Activity, 8(1), 98. doi:10.1186/14795868-8-98 PMID:21936895

Trinidad, S., Aldridge, J., \& Fraser, B. (2005). Development, validation and use of the online learning environment survey. Australasian Journal of Educational Technology, 21(1). Advance online publication. doi:10.14742/ ajet.1343

Tugade, M. M., Fredrickson, B. L., \& Feldman Barrett, L. (2004). Psychological resilience and positive emotional granularity: Examining the benefits of positive emotions on coping and health. Journal of Personality, 72(6), 1161-1190. doi:10.1111/j.1467-6494.2004.00294.x PMID:15509280

Uher, I., Cimboláková, I., \& Pivovarník, J. (2016). Physical activity and health. Sport and Tourism Central European Scientific Journal, 15(3), 67-74. PMID:25830559

Wei, C. W., Chen, N. S., \& Kinshuk, . (2012). A model for social presence in online classrooms. Educational Technology Research and Development, 60(3), 529-545. doi:10.1007/s11423-012-9234-9

Zandvliet, D. B., \& Straker, L. M. (2001). Physical and psychosocial aspects of the learning environment in information technology rich classrooms. Ergonomics, 44(9), 838-857. doi:10.1080/00140130117116 PMID:11560365

Zandvliet, D. B., \& Fraser, B. J. (2004). Learning environments in information and communications technology classrooms. Technology, Pedagogy and Education, 13(1), 97-123. doi:10.1080/14759390400200175

Zandvliet, D. B., \& Fraser, B. J. (2005). Physical and psychosocial environments associated with networked classrooms. Learning Environments Research, 8(1), 1-17. doi:10.1007/s10984-005-7951-2 
Lixin Zhao received his master's degree in Computer Software and Theory in Beijing Normal University. Now, he is a lecturer in the Department of Communication and a member in the Institute of Advanced Studies in Humanities and Social Sciences in Beijing Normal University, Zhuhai Campus. He is studying for his doctorate in Department of Computer Science \& Information Engineering, National Central University. His research interests include online learning, digital media, Internet communication.

Wu-Yuin Hwang received his Ph.D. degree in Computer Science in 1997 and currently a distinguished Professor of the Graduate Institute of Network Learning Technology, National Central University, Taiwan. Dr. Hwang has published over 60 papers in major international computer education journals indexed by SSCl and SCI. From 2000, he has earned four best paper awards of 4th, 8th, 9th and 13th Global Chinese Computer Conference (GCCC) in Education in Singapore, Hong Kong, Hawaii and Taipei in 2000, 2004, 2005 and 2009 respectively. Owing to the active contributions of academic research to National Science Council, Taiwan, Dr. Hwang received the TaYou Wu, Memorial Award from National Science Council in 2005. He is associate editor of International Journal of Distance Educa tion Technologies since 2011, the co-editor of special issue "The Disruptive Power of VR and Serious Games for Education" of Interactive Learning Environments(SSCI) in 2010, the co-editor of the special issue "Innovations in designing mobile learning applications" of Educational Technology \& Society (SSCI) in 2009, on the Reviewer Board of Educational Technology \& Society (SSCI) in 2007.

Timothy K. Shih is a Distinguished Professor and the Vice Dean of College of EECS at the National Central University, Taiwan. He is also the Director of Innovative Al Research Center. He was the Dean of the College of Computer Science, Asia University, Taiwan and the Chairman of the CSIE Department at Tamkang University, Taiwan. Prof. Shih is a Fellow of the Institution of Engineering and Technology (IET). He was also the founding Chairman Emeritus of the IET Taipei Local Network. In addition, he is a senior member of ACM and a senior member of IEEE. He was the founder and co-editor-in-chief of the International Journal of Distance Education Technologies, USA. He is the Associate Editor of IEEE Computing Now. And, he was the associate editors of the IEEE Transactions on Learning Technologies, the ACM Transactions on Internet Technology, and the IEEE Transactions on Multimedia. Prof. Shih's current research interests include Multimedia Computing, ComputerHuman-Interaction, and Deep Learning. 